Original Research Article

\title{
Variation in patterns of superficial vein of cubital fossa
}

\author{
Jiwanesushil ${ }^{1}$, Gajbhiye $V^{2}$, Jiwane $\mathbf{R}^{3}$ \\ ${ }^{1}$ Dr. Sushil Jiwane, Department of Anatomy, Gandhi Medical Collage Bhopal, India, ${ }^{2}$ Dr. Vivekannad Gajbhiye, \\ Department of Anatomy, ${ }^{3}$ Dr. Rekha Jiwane, Department of Physiology, ${ }^{2,3}$ authors are affiliated with RKDF \\ Medical Collage and Research Centre, Bhopal, MP, India
}

Address for Correspondence: Dr.Sushil Jiwane, Assistant Professor, Anatomy, Gandhi Medical Collage, Bhopal. Email: jiwanesushil@gmail.com

\begin{abstract}
Aim: To determine anatomical variations of superficial veins of cubital fossa. Background: The cubital fossa Veins lie superficially in the subcutaneous tissue and not paired with any artery, they are easy to view and access. The superficial veins include the cephalic, basilic, median cubital, and antebrachial veins and their tributaries. The knowledge of superficial venous distribution of the cubital fossa is important, not only from an anatomical-clinical and surgical point of view, but also anthropologically and biologically. Materials and Methods: The study done on 120 males and 30 females were randomly selected from among the rural area of central India which also include the students and staff members of J.N.M. College Sawangi Wardha (M.S.) 150 cases of right upper limbs and 150 cases of left upper limbs. After taking the subject's consent, the superficial veins of the cubital fossa were made prominent by using tourniquet. The patterns of cubital veins were marked on skin and photograph are taken. Results: the patterns of arrangement of superficial cubital vein observed are as follow. Type I-MCoVjoining with the $\mathrm{CV}$ and $\mathrm{BV}$ in $51 \%$, type II CV bifurcating into MBV and MCV which join $\mathrm{BV}$ and $\mathrm{ACV}$ respectively, Type III-MVF bifurcating in MBV and MCV 9.66\%., Type IV- 7.66\% subjects of present study the CV terminates in to BV and ACV runs separately, In Type V- 3\% of subjects the $\mathrm{CV}$ communicating directly with $\mathrm{BV}$ and $\mathrm{ACV}$ was absent and Type $\mathrm{VI}-\mathrm{A}$ large single $\mathrm{CV}$ ascending upwards without any communication with other veins. 3 of 300 subjects i.e. $1 \%$. Conclusion: Numerous studies in different races and ethnic groups have shown similarities and differences in the deposition of the superficial veins of the cubital fossa. Various procedure should be perform with caution bearing in mind the anatomical variation present in these region.
\end{abstract}

Keywords: Cubital fossa, Superficial veins, Cephalic vein, Basillic vein and Median Basilic vein.

\section{Introduction}

The superficial veins of the cubital fossa in man has been a topic of interest to anatomists, morphologists and anthropologists as well, for professionals in the field of health who must constantly intervene in this region[1].

Thecubital fossa Veins lie superficially in the subcutaneous tissue and not paired with any artery, they are easy to view and access[2]. The superficial veins include the cephalic, basilic, median cubital, and ante brachial veins and their tributaries. Most of these veins originate in the subcutaneous tissue

Manuscript received: $10^{\text {th }}$ November 2017

Reviewed: $20^{\text {th }}$ November 2017

Author Corrected: $26^{\text {th }}$ November 2017

Accepted for Publication: $1^{\text {st }}$ December 2017 on the dorsum of the hand from the dorsal venous network[3]. These veins are commonly used for blood sample collection, intravenous injections, venipuncture, blood transfusion, infusion, and in the last decades, are being used for the introduction of catheters in the collection of blood from the cardiac chambers and for the performing angiocardiographies, under emergency condition [4]. Cephalic vein used for construction of an arteriovenous fistula at wrist.

Basillic vein and Median Basilic vein for central venous catherization because it appears more voluminous. Despite of the importance of the approaching superficial veins, however, students in 
Original Research Article

the health care system usually have rare opportunities to observe actual human superficial vein, including anatomy cadavers. Further more, application of educated anatomical knowledge to the practical venipuncture procedure is difficult work because of variation of the anatomy of superficial vein $[5,6]$.

Because of the wide variations of these superficial veins, it has been reported that adverse effects such as bruising, hematoma, and sensory change occurred by mispuncture in various health care system $[7,8]$.

For the accomplishment of venipuncture of these superficial veins without such accidents, it is important to understand the courses of the superficial veins.

The knowledge of superficial venous distribution of the cubital fossa is important, not only from an anatomical-clinical and surgical point of view, but also anthropologically and biologically. The Present study was carried out toknow more about the anatomical variationsof superficial veins of cubital fossa.

\section{Material and Method}

It is anobservational study done attertiary care hospital and teaching institute of central India

Place of study: In this study 120 males and 30 females were randomly selected from the rural area and tied around mid-arm level. of central India. Students and staff members of J.N.M. College Sawangi Wardha (M.S.).

Inclusion criteria: 300 subjects aged between 18 and 70 years (mean, 52.6 years) were takenin the study. 150 cases of right upper limbs and 150 cases of left upper limbs.

Exclusion criteria: Persons with thick skin or wound within the cubital region were excluded from the study.

Sampling method: After taking the subject's consent, the superficial veins of the cubital fossa were made prominent by using tourniquet or Blood Pressure cuff at the right and left arm of subjects

They are asked to perform repeated flexion and extension simultaneously to make the vein become prominent. (active movement of forearm.)

Sample Collection: All 300 patterns ofcubitalveins were marked on skin and photograph are taken by using a Camera, with name, age, sex of a subjects. Small veins were ignored.

All the photographsobtained were carefully studied and analyzed.

Statistical Analysis: Data was expressed as mean \pm SD. Level of significance was considered at $P<$ 0.05 .

\section{Results}

Same patterns are observed by various workers but percentagesvary in different studies. However unilateral variation is found in $1.9 \%$ of studies by various workers.

Commonestobservation are type 1-V. Irrespective of sex and side. Our observationsare.

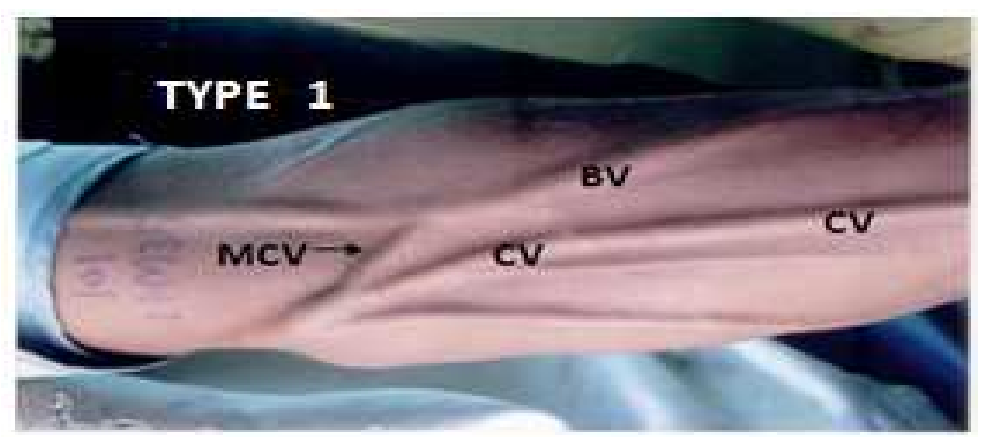

TYPE-1: Median cubital vein joining the cephalic vein \& basilic vein in.51\% 
Original Research Article

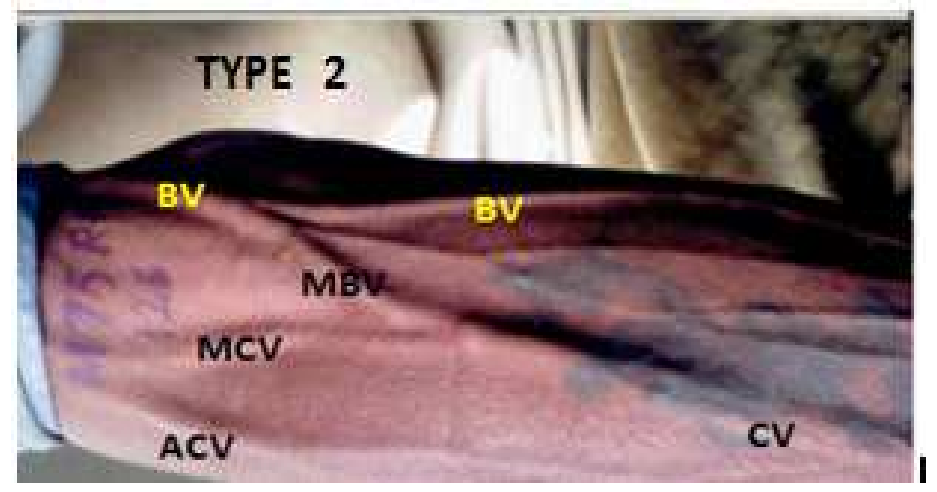

TYPE-2: Cephalic vein bifurcate into median basilic vein, \& median cephalic vein, which join the accessory cephalic vein \&basilic vein respectively.28\%

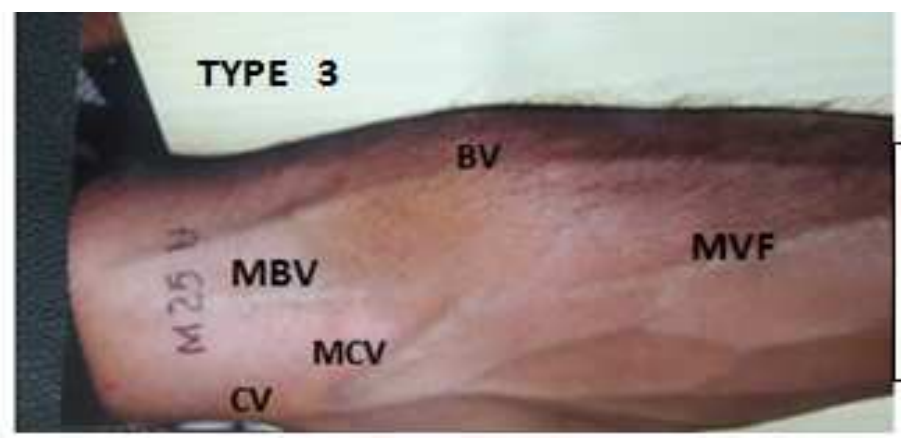

TYPE-3: Median vein of forearm divides in to median cephalic vein,medianbacilic vein which join the cephalic vein \&bacilic vein respectively. $11 \%$.

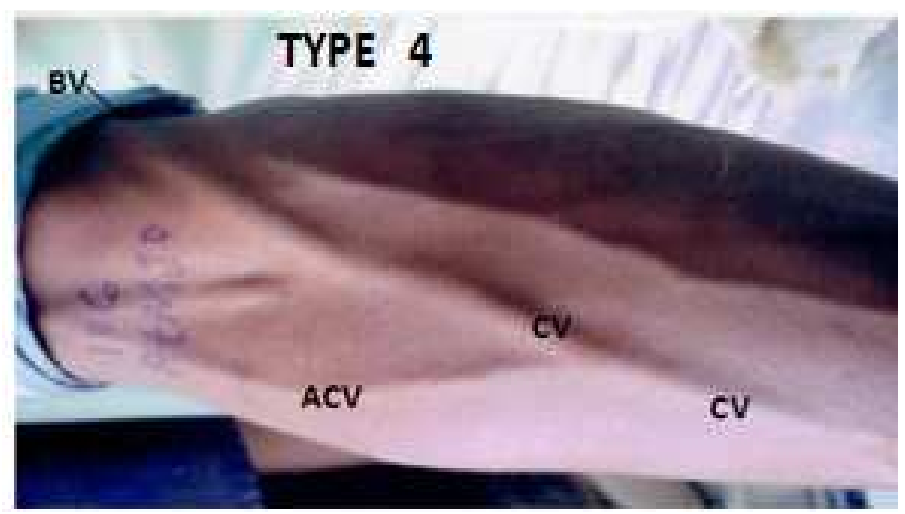

TYPE-4: Cephalic vein terminates into basilic vein \& accesory cephalic vein continued in the arm in place of cephalic vein. $9.3 \%$.

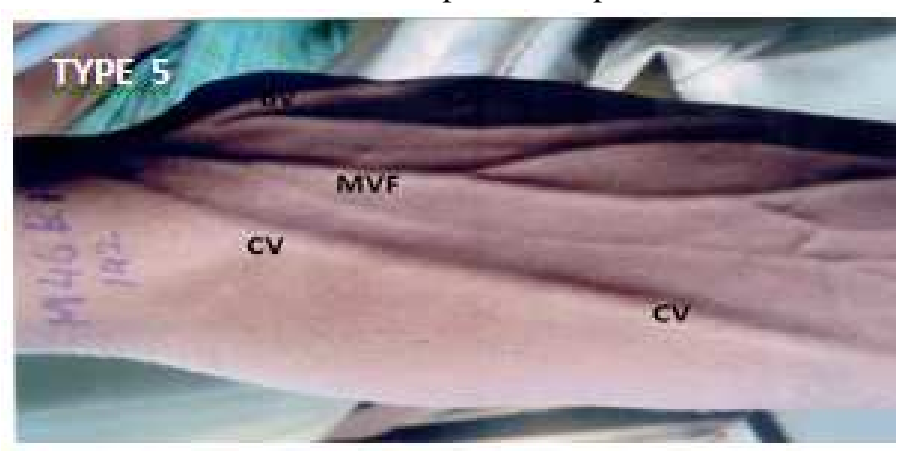

TYPE-5: Cephalic vein terminates into basilic vein in cubital fossa within absence of other veins . $3 \%$ 


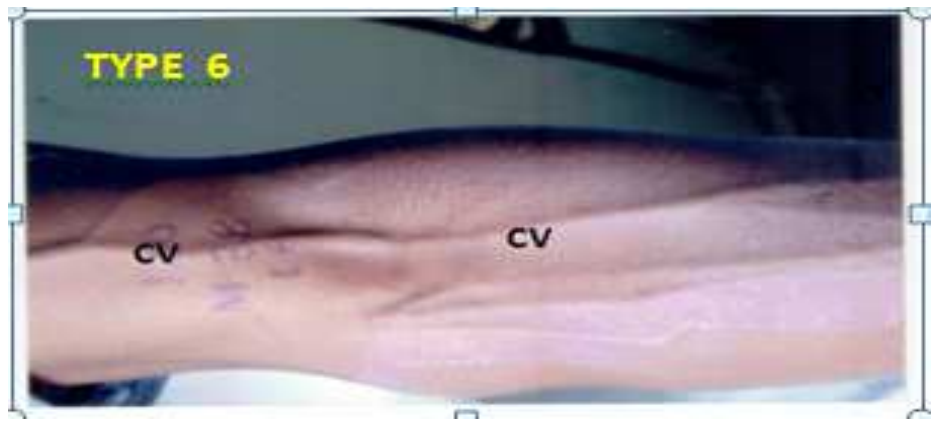

TYPE-6: A large cephalic vein singly passing upwards in front of cubital fossa without any communicationthroughout. 1.3\%

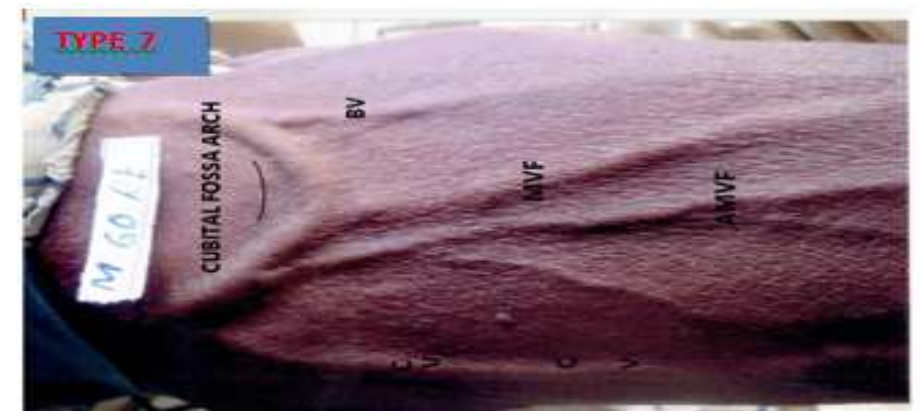

TYPE-7: Cubital venous arch formed by union of basilic vein, cephalic vein\& median vein of forearm unilatrally observed in a male 1 out of 300 examined limbs. $033 \%$

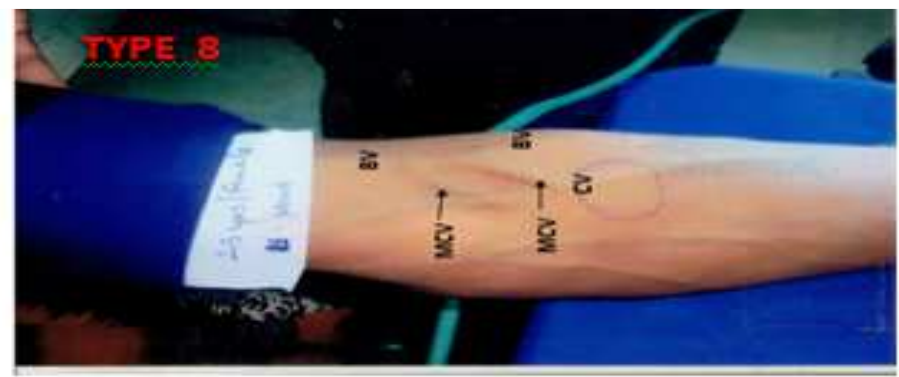

TYPE-8: Basilic vein and cephalic vein connected

by two different median cubital veins in a female, unilateraly. $0.3 \%$.

Table-1: Venous Pattern Observation on Cubital Fossa.

\begin{tabular}{|c|c|l|c|}
\hline 1 & Type 1 & Median cubital vein joining the cephalic vein \& bacilic vein & $51 \%$ \\
\hline 2 & Type 2 & $\begin{array}{l}\text { Cephalic vein bifurcates into median bacilicvein\& median cephalic vein,which } \\
\text { join the accessory cephalic vein \& bacilic vein respectively }\end{array}$ & $28 \%$ \\
\hline 3 & Type 3 & $\begin{array}{l}\text { Median vein of forearm divides in to median cephalic vein,medianbacilic vein } \\
\text { which join the cephalic vein \&bacilic vein respectively }\end{array}$ & $11 \%$ \\
\hline 4 & Type 4 & $\begin{array}{l}\text { Cephalic vein terminates into basillic vein and accessory cephalic vein } \\
\text { continued in the arm in place of cephalic vein.7.66\% no communication }\end{array}$ & $9.33 \%$ \\
\hline 5 & Type 5 & $\begin{array}{l}\text { Cephalic vein terminates into bacilic vein in cubital fossa within absence of } \\
\text { other veins }\end{array}$ & $3 \%$ \\
\hline 6 & Type 6 & $\begin{array}{l}\text { A large cephalic vein singly passing upwards in front of cubital } \\
\text { fossawithoutany communication throughout. }\end{array}$ & $1.3 \%$ \\
\hline 7 & Type 7 & $\begin{array}{l}\text { Cubital venous arch formed by union of basilic vein,cephalic vein\& median } \\
\text { vein of forearm unilaterally observed in a male1 out of 300 examined limbs. }\end{array}$ & $.033 \%$ \\
\hline 8 & Type 8 & $\begin{array}{l}\text { Basilic vein and cephalic vein connected by two different median cubital veins } \\
\text { in a female,unilaterally. }\end{array}$ & $0.3 \%$ \\
\hline
\end{tabular}




\section{Discussion}

The arrangement of the superficial veins in the cubital fossa is subject to considerable variation [9]. In the present study the patterns of arrangement of superficial cubital vein were observed as follows:-

The most common finding observedwas that of Type I-MCoVjoining with the CV and BV in 51\% of subjects.

This finding matches the various text books descriptions by Mcgragor and plessis. William and Warwick, 19[9]. The percentage of Type IMCoV joining the $\mathrm{CV}$ with $\mathrm{BVwere}$ varies between 52 $84 \%$.

However Tewari et al [10] reported the incidence of such patterns is only $6 \%$ whereas Usha Dhall[11] observed $74.5 \%$ which is more than observe by otherresearchers. In the present study only $51 \%$ of subjects having this type of pattern.

The second commonest finding in present study was type II CV bifurcating into $\mathrm{MBV}$ and $\mathrm{MCV}$ which join BV and ACV respectively which is 27\%. Same Type II patternwere observed by Usha Dhall et.al[11].

Next commonest pattern in present study was Type III-MVF bifurcating in MBV and MCV 9.66\%. Similar pattern of Type III was observed by Tewariet. alwhich is $21 \%$ [10].However low incidence of such pattern had been reportedby Usha Dhall et al. i.e. $4 \%$ only which is very low.

In Type IV- 7 . In about $66 \%$ of subjects in present study shows the pattern in whichCV terminates in to $\mathrm{BV}$ and $\mathrm{ACV}$ runs separately. Similar observation were found by Tewari et al. (1971) [10] which is $10 \%$ in Indian subjectsand $14 \%$ in Japanese observed by Okamoto[12]. According to S.P. Singh et.al[13] (1982) $10 \%$ of Nigerians show this type of patterns of veins. However Usha Dhallet. Al [11] reported such finding in $6.5 \%$ of the Indian subjects.

In Type $\mathrm{V}$ - I n present study onlyin $3 \%$ of subjects the $\mathrm{CV}$ communicating directly with $\mathrm{BV}$ and $\mathrm{ACV}$ was absent. Similar finding $2 \%$ was observed by Usha Dhall et.al[11] in Indian subjects.
Other notable findings in present study that were not reported by researchers in the past are-

- In our study we found variations in patterns of veins Type VI,Type VIII, Type VIII that is very rare only one percent of subject show such type of variations.

- Type VI -A large single CV ascending upwards without any communication with other veins. 3 of 300 subjects i.e. $1 \%$.

- Type VII- Cubital venous arch formed by the $\mathrm{BV}, \mathrm{CV}$ and MVF as an unilateral presentation in the 1 of 300 subjects $.33 \%$.

- Type VIII- Basilic vein and cephalic vein connected by two different median cubital veins in a female, unilaterally $0.3 \%$.

- BV- Basilic vein, CV-Cephalic vein, ACVAccessory cephalic vein, MCoV- median cubital vein, MVF-median vein of forearm (abbreviation used are the same for all photographs).

\section{Conclusion}

Numerous studies in different races and ethnic groups have shown similarities and differences in the deposition of the superficial veins of the cubital fossa. Various procedure like vein puncture should be perform with caution bearing in mind the anatomical variation present in these regions. Awareness of the uncommon cubital venous patterns and their incidence makes for a more direct approach to these veins, especially under emergency conditions.

Clinical significance: In the recent decades the veins of the cubitalfossa are used in manymore specialized intervention and important as the realization of angiocardiograms, with some traditional diagnostic and therapeutic procedures.

An awareness of these uncommon arrangements of superficial cubital veins, such as absence of median cubital and cephalic veins and double or arched median cubital vein, and their percentages of occurrence would be important when locating veins for venipuncture or venesection. 
Funding: Nil, Conflict of interest: None Permission of IRB: Yes

\section{References}

1. Standring S, editor. Gray's Anatomy. 41st ed. Edinburg: Elsevier Health Sciences; 2016.

2. Snell RS. Clinical anatomy by regions., 9th ed. Baltimore: Lippincott Williams \& Wilkins; 2012.

3.Williams PL, Bannister LH, Berry MM, Collins P, Dyson M, Dussek JE.et al. Gray's Anatomy. 38th ed. Edinburgh UK: Churchill Livingstone; 1995.

4. Pyes KJ. Surgical Handicraft, 20th ed. Bristol: John Wright and Sons Ltd; 1977.

5. Moore KL, Dalley AF, Agur AM. Clinically oriented anatomy. Lippincott Williams \& Wilkins; 2013.

6.Warwick R, Williams PL. Gray's anatomy, 35th ed. Edinburgh: Longman;1973.

7. Newman BH, Pichette S, Pichette D, Dzaka E. Adverse effects in blood donors after whole-blood donation: a study of 1000 blood donors interviewed
Original Research Article

3 weeks after whole-blood donation. Transfusion. 2003;43:598-603.

8. Newman B, Waxman D. Blood donation-related neurologic needle injury: evaluation of 2 years' worth of data from a large blood center. Transfusion. 1996;36(3):213-215.

9. Warwick R, Williums R. Grays anatomy (36 edition) London, Churchill Livingstone.

10.Tewari SP, Singh SP, Singh S. The arrangement of superficial veins in cubital fossa in Indian subjects. J Anat Soc India. 1971;20 (2):99-102.

11. Usha D, Gopinathan and K, Dhall J. C. Superficial veins of the cubital fossa in Indian subjects. Anatomical Adjuncts. 1985; (1): $39-45$.

12.Okamoto P. The arrangement of the superficial veins of the cubittal fossa in Japanese men. Anat Rec. 1922;154:276-8.

13. Singh SP, Ekandem GJ, Bose S. A study of the superficial veins of the cubital fossa in Nigerian subjects. Cells Tissues Organs. 1982; 114 (4): 317-20.

\section{How to cite this article?}

Jiwanesushil, Gajbhiye V, Jiwane R.Variation in patterns of superficial vein of cubital fossa. Int J Med Res Rev 2017;5 (12):976-981.doi:10.17511/ijmrr. 2017.i12.02 